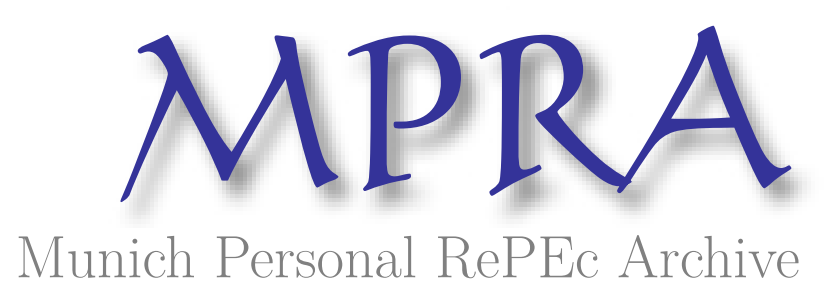

\title{
Group Decision-Making and Voting in Ultimatum Bargaining: An Experimental Study
}

Elbittar, Alexander and Gomberg, Andrei and Sour, Laura

2011

Online at https://mpra.ub.uni-muenchen.de/66067/

MPRA Paper No. 66067, posted 30 Sep 2015 04:47 UTC 


\title{
The B.E. Journal of Economic Analysis \& Policy
}

\section{Contributions}

\section{Group Decision-Making and Voting in Ultimatum Bargaining: An Experimental Study}

\author{
Alexander Elbittar* Andrei Gomberg ${ }^{\dagger}$
}

Laura Sour

${ }^{*}$ Centro de Investigación y Docencia Económicas, alexander.elbittar@cide.edu

†Instituto Tecnológico Autónomo de México, gomberga@gmail.com

†Universidad Anáhuac México Norte, laura.sour@anahuac.mx

\section{Recommended Citation}

Alexander Elbittar, Andrei Gomberg, and Laura Sour (2011) "Group Decision-Making and Voting in Ultimatum Bargaining: An Experimental Study," The B.E. Journal of Economic Analysis \& Policy: Vol. 11: Iss. 1 (Contributions), Article 53.

Available at: http://www.bepress.com/bejeap/vol11/iss1/art53

Copyright (C)2011 Berkeley Electronic Press. All rights reserved. 


\title{
Group Decision-Making and Voting in Ultimatum Bargaining: An Experimental Study*
}

\author{
Alexander Elbittar, Andrei Gomberg, and Laura Sour
}

\begin{abstract}
We conduct a laboratory study of the group-on group ultimatum bargaining with restricted within-group interaction. In this context, we concentrate on the effect of different within-group voting procedures on the bargaining outcomes. Our experimental observations can be summarized in two propositions. First, individual responder behavior across treatments does not show statistically significant variation across voting rules, implying that group decisions may be viewed as aggregations of independent individual decisions. Second, we observe that proposer behavior significantly depends (in the manner predicted by a simple model) on the within-group decision rule in force among the responders and is generally different from the proposer behavior in the one-on-one bargaining.
\end{abstract}

KEYWORDS: bargaining games, group decision making, experimental design

${ }^{*}$ We would like to thank Gary Bornstein, Gary Charness, Vincent Crawford, Robert Duval, Sonia Di Giannatale, David Kaplan, John Kagel, Martin Kocher, David Levine, Eric Magar, Cesar Martinelli, Martin Osborne, Charlie Plott, Al Roth, Andrew Schotter, and Tridib Sharma. We also thank the Editor and the three anonymous referees for the valuable comments on our submitted manuscript, as well as participants of the 2nd World Congress of the Game Theory Society, 2004 North American and 2005 International ESA Meetings, 2005 Public Choice Society Meetings, 2005 Cancún Political Economy Workshop, 2005 SAET Meetings, 2005 World Congress of the Econometric Society, seminars at Universidad Carlos III, NES/CEFIR, ITAM, UNAM, Colegio de México and CIDE for their helpful advice, Gabriela Calderón, Esteban Colla, Carlos Lever, Demián Reyes and Arám Zamora for assistance in running the experiments, and Abelardo León for assistance in programming. Financial support from the Ford Foundation-CIDE and Asociación Mexicana de Cultura is also acknowledged. To contact Elbittar at CIDE: alexander.elbittar@cide.edu. To contact Gomberg at ITAM - CIE: gomberg@itam.mx. To contact Sour at Universidad Anáhuac México Norte: laura.sour@anahuac.mx. 
Elbittar et al.: Group Decision-Making and Voting in Ultimatum Bargaining

\section{Introduction}

Many common bargaining situations, such as those that occur between states, between branches of government or between legislative factions, between corporate management and shareholders, unions and employers, etc. involve interactions between groups rather than between individuals. In such circumstances, it is natural to believe that intra-group decision-making rules must affect bargaining outcomes. This theoretical observation is, of course, not new, dating, in the context of international relations, back to, at least, Schelling (1980), who conjectured that domestic ratification constraints might serve to strengthen the executive's position vis-a-vis foreign governments compared with what would have obtained if such constraints didn't exist.

The application of this argument, of course, crucially depends on two assumptions. Firstly, in order for the effect of the explicit group decisionmaking rules used to be clear, one needs to assume that these rules merely aggregate individual decisions that, on their own, are not affected by the explicit group decision-making rules postulated. Secondly, taking the former as the case, the entire argument presumes that opposing negotiators are capable of internalizing the impact of their opponents' internal decision-making processes. Our present work is focused on empirically testing the latter part of the argument: the ability of agents to react to the formal rules, regulating the decision-making in the opposing camp.

We attempt to do this in a context of a laboratory study of ultimatum bargaining. ${ }^{1}$ In this game, one side (the proposers) suggests how to partition a total available payoff between itself and the other side (the responders), who, in turn can accept or reject the proposal. In case of acceptance the proposal is implemented, while in case of rejection neither side receives anything. As is well-known, the subgame-perfect equilibrium outcome is for the ultimatumproposer to receive (almost) the entire surplus. In contrast, in laboratory implementation of the game, ultimatum-responders consistently obtain a significant, though smaller, share. We replace the unitary bargainers with two sides, consisting of multiple subjects each. The group decision-making rules among the responders vary across treatments and we concentrate on comparing the proposer behavior that emerges when faced with differently structured

\footnotetext{
${ }^{1}$ Our choice of the simplest possible bargaining procedure, originally introduced in the lab by Güth et al. (1982), is mainly dictated by the ease of its experimental implementation and by the straightforward interpretation of the experimental results in this setting. The common regularities established by the vast experimental literature are summarized by Roth (1995) and Camerer (2003).
} 
opponents. Given this objective, we would like to, as much as possible, avoid the impact that belonging to a group using a certain rule to make a decision might exert on individual behavior. For this reason we design an environment in which subjects' ability to communicate or create personal links is minimized. In particular, responders vote on whether to accept or reject an offer without any contact with other members of their group, without even knowing their identity. We conjecture that in such a setting individual responder behavior would not depend on how the group decision is derived from individual votes (something we shall explicitly test for). This, if true, would allow for a clear comparison between the incentives faced by proposers facing responders operating using different explicit rules.

Our experimental observations can be summarized in two propositions. First, individual responder behavior across treatments does not, indeed, show statistically significant variation across treatments. Second, we observe that proposer behavior significantly depends (in the manner predicted by a simple model) on the intra-group decision rule in force among the responders, and is generally different from the proposer behavior in the one-on-one bargaining. This suggests that subjects are able to internalize the different nature of the responders across the treatments.

There does exist a notable literature on ultimatum bargaining between groups. Thus, Bornstein and Yaniv (1998) have suggested that when the ultimatum game is played by unstructured groups of agents, rather than by individuals, the division of the payoff is substantially affected in favor of the ultimatum-proposers, who seem to behave more aggressively, facing effectively more passive group opponents. Whether that effect is due to the implicitly emerging procedures among the responders or to changes in individual behavior induced by group membership remains unclear. In general, the within-group decision-making may be difficult to observe or categorize, unless it is explicitly imposed. But imposing some preference aggregation rule may have a direct impact on the way the game is played, as suggested, at least for the case of the trust game, by Song (2009). A distinct question is to what extent explicitly imposed intra-group decision rules themselves matter for the behavior of the opposing side. Here the evidence so far is extremely limited. In a previous study by Messick et al. (1997), who, like us, limit the within-group interactions, the answer seems to be negative: proposers behave the same, whatever decision rule is imposed on the responders (though, given the low number of observations in this study, the lack of statistically significant difference is, at best, inconclusive). This result is echoed in Bosman et al. (2006), who 
observe no difference between proposer behavior when faced with individual or group responders in a similar power-to-take game (unlike us, they do explicitly allow and study communication within groups). While the previously mentioned studies look at single-shot bargaining between inexperienced subjects, Grosskopf (2003) studies behavior changes as agents learn from their experience. Comparing one-on-one and one-on-group ultimatum bargaining when unanimity is required for rejection (a rule similar to that in one of the treatments in the previously cited work by Messick et al.) she finds that, though the agents might not be able to figure out the difference immediately, with experience a clear difference emerges between the play against groups versus play against individuals (something that we also find). In particular, she observes that, when playing against groups requiring unanimity to reject, proposers eventually learn to be more aggressive than when playing against individuals. On the whole, the issue remains underexplored.

The results of this paper provide empirical support for the abovementioned Schelling's (1980) conjecture and for the substantial theoretical literature that grew out of it. Thus, for instance, Putnam (1988), in describing the linked problems of domestic politics and international negotiation, explicitly notes the role of varying ratification procedures in bargaining situations; the same observation has been made formally, among others, by Haller and Holden (1997), who concluded that the supermajority treaty ratification requirement imposed by the U.S. constitution may, indeed, advantageously affect that country's negotiating positions. In a related context, Manzini and Mariotti (2005) suggested that unanimity-based decision-rules within alliances should make them more successful in negotiations compared with coalitions governed by majority rule. The assumption that agents are cognizant of the impact of intra-group institutions on inter-group bargaining is also implicit in Romer and Rosenthal (1978 and 1979) work on political resource allocation, in which the monopoly agenda-setter effectively bargains with the median voter, thus internalizing the majority voting used in a democracy. We believe that our experimental findings provide some support for the theoretical conclusions of all of these papers. If the explicit rules are transformed by within-group interaction affecting individual choices, as suggested, for instance, by Song (2009), or if the bargainers are unable to react to their opponents' internal structure, this would profoundly affect the theoretical arguments here mentioned. We believe, our work indicates that, at least in an environment where group members are united only by sharing the bargaining outcomes, the implicit assumptions of much of the theoretical literature are sustained. 
Our work also relates to the empirical literature on intergroup interaction in games developed by social psychologists. Wildschut et al. (2003) provide a "meta-study" of a large body (involving some 130 papers) of experimental evidence on what is known in psychology as the group discontinuity effect: the general tendency of groups of agents to behave more aggressively than individuals in similar circumstances, whether due to social reinforcement of aggressive behavior, greater anonymity within the group, or fear of aggressive behavior by the opposing group. More recently, the issue has been taken up by economists and economic psychologists, who compared the degree to which group and individual play conforms to the game-theoretic predictions. Thus, we have already mentioned a study by Bornstein and Yaniv (1998) on group ultimatum games, while Bornstein et al. (2004) see earlier group exit in the centipede game, both pointing towards the backward induction outcomes of these games. Robert and Carnevale (1997) observe that in a group-ongroup ultimatum game that proposer groups tend to follow the preferences of its "most competitive" member. ${ }^{2}$ Similarly, Cox (2002) observes that in an investment game group decisions correspond to those of their most aggressive members, which makes them most closely "game-theoretic" in terms of monetary payoffs. Kocher and Sutter (2007) observe more aggressive group behavior to prevail in a gift-exchange experiment even when group members are not allowed any face-to-face interaction but reach a decision via a computer communication protocol. In contrast, in a context of the dictator game Cason and Mui (1997) observe that more generous (other-regarding) agents dominate group decisions. Overall, the issue remains unsettled, and Camerer (2003) includes further study of the manner in which groups act in games as one of the ten top open research questions in behavioral economics. In this work we concentrate on what sort of difference between group and individual play could be ascribed to implicit preference aggregation rules within groups, which might be emerging endogenously, when not explicitly imposed, even when no real intra-group interaction, except through the decision rule and sharing the common outcome, is involved.

The rest of this paper is organized as follows: section 2 derives the theoretical predictions of our experimental framework and discusses the experimental design; section 3 presents laboratory results; section 4 concludes.

\footnotetext{
${ }^{2}$ They elicit the individual preferences from observations of one-on-one play by the same agents.
} 


\section{The Model and Experimental Design}

We start by providing a simple incomplete information model of ultimatum bargaining, specified to the extent we shall be able to implement it in the lab. We consider an environment, in which a monetary prize of $\pi>0$ is to be shared between the two sides: proposers and responders. In a one-on-one ultimatum bargaining, the proposer has to choose a number $x \in[0, \pi]$ that she will offer to the responder, with the balance of $\pi-x$ being left to herself. Following Kennan and Wilson (1993), we model an asymmetric information game, in which proposers do not observe the minimal offer size $x_{r} \in[0, \pi]$, below which a responder chooses to reject (the responder's type). Proposers believe that this $x_{r}$ is drawn from some probability distribution with the support $[0, \pi]$ with the distribution function $F(x)$. Clearly, $F(x)$ can be interpreted as the acceptance probability of offer $x$, while $P(x)=1-F(x)$ is the probability of rejection. If the proposer is an expected utility maximizer with the Bernoulli utility function of final wealth $w$ given by $u(w)$, then, if she offers $x$, her expected payoff is given by

$$
\Pi(x)=u(\pi-x)(1-P(x))
$$

In what follows we shall assume that $u$ and $P$ are twice continuously differentiable with $u^{\prime} \geq 0, u^{\prime \prime} \leq 0$ and $P^{\prime} \leq 0$. In other words, we shall assume that the proposer likes money, is either risk-neutral or risk-averse and believes the probability of rejection to be decreasing in the offer size. We shall further assume that $P\left(\frac{\pi}{2}\right)=0$ (if you give at least as much to the responder as you keep for yourself she always accepts) and $P(0)=1$ (offers of nothing are always rejected), both of which are very robust empirical regularities observed in ultimatum game experiments. These assumptions clearly imply impossibility of corner solutions to the proposer's maximization problem. The first order necessary condition for expected utility maximization in the interior (which is easily seen to be sufficient if $P(x)$ is convex at $x)$ is

$$
u^{\prime}(\pi-x)(1-P(x))=-u(\pi-x) P^{\prime}(x)
$$

It is worth noting, that at the optimum $P(x)<1$ (since $P(x)=1$ would guarantee a zero payoff).

Consider now the same ultimatum bargaining between groups of three proposers and three responders for a prize $3 \pi$ (though we are not concentrating on the proposers here, we chose to make them also consist of 3 subjects to 
maintain payoff symmetry of the one-on-one bargaining). The proposers' share of the prize will be divided equally between the proposers and the responders' share between the responders. An ultimatum $x$ shall mean that each proposer gets $\pi-x$, and each receiver gets $x$. Under these conditions the pair $(x, \pi-x)$ continues to completely describe the distribution of the monetary payoffs in case of acceptance.

In total we consider 4 different treatments: the control one-on-one ultimatum bargaining and 3 group-on-group treatments specified in terms of the responder group voting rule. ${ }^{3}$ The following sums up the treatments:

Individual bargaining (I): one agent, the proposer, suggests a division of a fixed amount of money, and a second agent, the responder, accepts or rejects it. If the responder rejects, no individual receives any pay, and if he accepts, each individual receives the amount specified in the proposal

Unanimity with Rejection Default (URD): An offer is considered accepted when every member of the responder group votes to accept it. Otherwise it is considered rejected.

Unanimity with Acceptance Default (UAD): An offer is considered rejected when every member of the responder group votes to reject it. Otherwise it is considered accepted.

Majority Rule (MR): An offer is considered accepted when at least two members of the responder group vote to accept it. Otherwise it is considered rejected.

Assuming individual responder behavior $P(x)$ to be constant across treatments (a key assumption that we are going to test), group rejection probabilities and payoffs should vary predictably with the group, as summarized in the following table:

\footnotetext{
${ }^{3}$ We could have considered another alternative: the dictatorship (one agent chosen to make the decision to accept or reject for the entire group). Charness and Jackson (2007), found, in the context of the Stag Hunt game, that the dictator group-on-group game may be played differently from the one-on-one game (at least as far as equilibrium selection is concerned) due to a feeling of responsibility on the part of the dictator. Likewise, Song (2008) suggests that when individuals are intrusted with deciding for groups in the context of the trust game, their behavior is affected. We do not model it here though, so the dictator rule would be equivalent to the one-on-one game.
} 
Elbittar et al.: Group Decision-Making and Voting in Ultimatum Bargaining

\begin{tabular}{|c|c|c|}
\hline Treatment & Probability of rejection & Proposer's expected utility: $\Pi(x)$ \\
\hline \hline $\mathrm{I}$ & $P(x)$ & $u(\pi-x)(1-P(x))$ \\
\hline $\mathrm{MR}$ & $P^{3}(x)+3 P^{2}(x)(1-P(x))$ & $u(\pi-x)(1-P(x))^{2}(1+2 P(x))$ \\
\hline $\mathrm{UAD}$ & $P^{3}(x)$ & $u(\pi-x)\left(1-P^{3}(x)\right)$ \\
\hline $\mathrm{URD}$ & $1-(1-P(x))^{3}$ & $u(\pi-x)(1-P(x))^{3}$ \\
\hline
\end{tabular}

The first order necessary conditions for expected utility maximization, simplified by noticing that $P(x)<1$ in the optimum and dividing both sides of the condition for the MR by $(1-P(x))>0$ and the condition for URD by $(1-P(x))^{2}>0$, are as follows:

\begin{tabular}{|c|c|}
\hline Treatment & FOC Expected Utility Maximization (simplified) \\
\hline \hline $\mathrm{I}$ & $u^{\prime}(\pi-x)(1-P(x))=-u(\pi-x) P^{\prime}(x)$ \\
\hline $\mathrm{MR}$ & $u(\pi-x)(1-P(x))(1+2 P(x))=-6 u(\pi-x) P^{\prime}(x) P(x)$ \\
\hline $\mathrm{UAD}$ & $u(\pi-x)\left(1-P^{3}(x)\right)=-3 u(\pi-x) P^{\prime}(x) P^{2}(x)$ \\
\hline $\mathrm{URD}$ & $u(\pi-x)(1-P(x))=-3 u(\pi-x) P^{\prime}(x)$ \\
\hline
\end{tabular}

Without a further assumption on $P$, multiple local maxima are possible. Though global maximum, generically (in either $P$ or $u$ ), would be unique, multiplicity of local maxima might allow the global maximum to "jump" depending on the voting rule, which might create problems with identifying the impact of the rules. Unfortunately we do not directly observe $P$. However, the following assumption, which is satisfied by most "symmetric" models of rejection probability (such as linear, logit or probit), would avoid this problem.

Assumption A: $P(x)$ is (weakly) convex whenever $P(x) \leq \frac{1}{2}$.

Let $x_{U A D}$ be an agent's optimal proposal when the responder decision is taken under the UAD, $x_{U R D}$ - the same for the URD and $x_{M R}$ - for the MR; finally let $x_{I}$ be the optimal proposal in the standard one-on-one bargaining. We can now state the following proposition:

Proposition 1 Let assumption A hold. The optimal offers by any weakly riskaverse (including risk-neutral) individual in each treatment will be ranked as follows :

$$
x_{U A D}<x_{I}<x_{M R}<x_{U R D}, \quad \text { if } P(x)>\frac{1}{4}
$$


The B.E. Journal of Economic Analysis \& Policy, Vol. 11 [2011], Iss. 1 (Contributions), Art. 53

$$
x_{U A D}<x_{M R}<x_{I}<x_{U R D} \text {, if } P(x)<\frac{1}{4}
$$

Proof. The proof is done by comparing the first order conditions.

Since it has been assumed that $P(0)=1 ; P(\pi)=0$, the solution is interior. Furthermore, assumption A ensures that, as long as $P(x) \leq \frac{1}{2}$, the first order conditions are sufficient and that there is at most one local maximum for each voting rule in this range. But for all voting rules, other than UAD, this must be the global maximum, since the proposer can always ensure the payoff equal to $u\left(\frac{\pi}{2}\right)$ by offering to share the prize equally, which, as has been discussed above, will always be accepted.

Consider now the optimal offer $x_{I}$ in the one-on-one game. Then

$$
u^{\prime}\left(\pi-x_{I}\right)\left(1-P\left(x_{I}\right)\right)=-u\left(\pi-x_{I}\right) P^{\prime}\left(x_{I}\right)
$$

Comparing this with the first order condition for the UAD game, observe that

$$
u^{\prime}\left(\pi-x_{I}\right)\left(1-P^{3}\left(x_{I}\right)\right)>-3 u\left(\pi-x_{I}\right) P^{\prime}\left(x_{I}\right) P^{2}\left(x_{I}\right)
$$

as long as $P\left(x_{I}\right)<1$. Since offering a proposal that would spur rejection with probability one cannot be optimal for the proposer, the inequality must hold. The right-hand side is decreasing in $x$, the left is increasing in $x$, hence to restore equality $x$ has to be decreased for the optimum in the unanimity (with acceptance default) case to be achieved. Though unanimity with acceptance default is the only rule considered here for which the true global maximum might involve $P(x)>\frac{1}{2}$, that would imply even more aggressive behavior by the proposers, so that the conclusion that $x_{U A D}<x_{I}$ is maintained.

Similarly, for the URD game

$$
u^{\prime}\left(\pi-x_{I}\right)\left(1-P\left(x_{I}\right)\right)<-3 u\left(\pi-x_{I}\right) P^{\prime}\left(x_{I}\right)
$$

and $x$ has to be increased to get to the optimum (unique, since in this case, as noted above, $P(x) \leq \frac{1}{2}$ must hold at the maximum).

We have established that $x_{U A D}<x_{I}<x_{U R D}$. It can be similarly shown that $x_{U A D}<x_{M R}<x_{U R D}$. To establish the position of $x_{M R}$ vis a vis $x_{I}$ observe that (taking into account the first order condition for the individual case): if $P\left(x_{I}\right)<\frac{1}{4}$

$$
u^{\prime}\left(\pi-x_{I}\right)\left(1-P\left(x_{I}\right)\right)\left(1+2 P\left(x_{I}\right)\right)>-6 u\left(\pi-x_{I}\right) P^{\prime}\left(x_{I}\right) P\left(x_{I}\right)
$$


Elbittar et al.: Group Decision-Making and Voting in Ultimatum Bargaining

$$
\begin{aligned}
& \text { if } P\left(x_{I}\right)>\frac{1}{4} \\
& \qquad \begin{aligned}
u^{\prime}\left(\pi-x_{I}\right)\left(1-P\left(x_{I}\right)\right)\left(1+2 P\left(x_{I}\right)\right)<-6 u\left(\pi-x_{I}\right) P^{\prime}\left(x_{I}\right) P\left(x_{I}\right)
\end{aligned}
\end{aligned}
$$

To see the necessary direction of change of $x$ divide both sides of the previous inequality condition by $P(x)>0$ to get

$$
\frac{u^{\prime}\left(\pi-x_{I}\right)}{P\left(x_{I}\right)}\left(1-P\left(x_{I}\right)\right)\left(1+2 P\left(x_{I}\right)\right)<(>)-6 u\left(\pi-x_{I}\right) P^{\prime}\left(x_{I}\right)
$$

with the left-hand side increasing and the right hand side decreasing in $x$.

Empirical predictions summarized by the Proposition 1 admit a broad array of the shapes of $u$ and $P$. Furthermore, the (weak) risk-aversion and (weak) convexity of $P$ in the relevant part of the domain are not necessary and could be further relaxed.

Predictions for the play against the unanimity groups are very straightforward; less so with the case of the majority rule. Equilibrium offers depend on the proposers' degree of risk-aversion and the shape of the rejection probability $P(x)$, both of which we do not control for in the experiment. Both offers that face higher and lower rejection probability than $\frac{1}{4}$ are likely to be observed. However, we do have a qualitative prediction in that the less aggressive proposers in the one-on-one treatment should become somewhat more aggressive when playing against MR groups, while the initially more "aggressive" proposers are predicted to moderate their behavior somewhat in this case (though they would still be relatively more aggressive than the initially less aggressive types).

Our comparative statics prediction on group action is contingent on the individual rejection probability $P(x)$ being constant across treatments. Of course, if responders behavior is affected by the fact of being in the group and/or by the decision rule the group is using, this might not be the case. We shall explicitly test this assumption in the experimental environment with no within-group interaction among the responders other than voting itself.

In addition to the four independent design treatments discussed above, in order to test the model's prediction that a less (more) aggressive proposer in a one-on-one ultimatum bargaining becomes somewhat more (less) aggressive when playing against groups, we consider two sequential design treatments: in the first treatment, a one-on-one ultimatum bargaining is followed by a groupon-group ultimatum bargaining where the responder groups have to decide whether to accept using the majority voting rule. In the second treatment, 
we reverse the order by having the subjects play majority-rule group-on-group bargaining game before the one-on-one game.

We conducted three sessions of each of the independent design treatments, but only 1 session of each of the sequential design treatments, with between 24 and 30 subjects participating in each session Tables 1 and 2 summarize for each experimental design the treatments, the group size, and the number of subjects per session.

\subsection{Design Parameters}

This section describes the general experimental procedure.

Participants and Venue. Subjects were drawn from a wide crosssection of undergraduate students at Instituto Tecnológico Autónomo de México (ITAM) in Mexico City. The recruitment was done from among those enrolled in introductory classes, in order to avoid those exposed to higher-level economics courses, such as game theory. Each subject participated in only one session. The experiment was run at ITAM using computers.

Number of Periods. In order to familiarize subjects with the procedures, two practice periods were conducted before the 10 real (affecting monetary payoff) periods. For the sequential design, two practice periods were conducted before the 10 real periods in the first ultimatum bargaining, and one practice period was conducted before the 10 real periods in the second ultimatum bargaining.

Agent Types. For each of the group-on-group treatments, each participant was designated as a member of a type A group (i.e., proposers) or a member of a type B group (i.e., responders). For the one-on-one treatment, each participant was designated either as a type A agent (i.e., proposer) or as a type $\mathrm{B}$ agent (i.e., responder) before the beginning of the practice periods. All designations were determined randomly by the computer at the beginning of the experimental session, and remained constant during the entire session. For the sequential design, each participant type was determined at the beginning of a session and preserved across bargaining situations.

Matching Procedure and Group Size. For each of the group-on-group treatments, membership of each group was changed in a random fashion, so that each participant formed part of a new group (of the same type) at the beginning of each period. Each group consisted of three participants. For the one-on-one treatment, a type $\mathrm{A}$ agent was paired with a type $\mathrm{B}$ agent, and each pairing was randomized for each period. Furthermore, agents did not know who they were paired with in any given period. 
Elbittar et al.: Group Decision-Making and Voting in Ultimatum Bargaining

Table 1: Independent Design

\begin{tabular}{|c|c|c|}
\hline $\begin{array}{c}\text { Experimental Treatments of } \\
\text { the Ultimatum Bargaining }\end{array}$ & $\begin{array}{c}\text { Group } \\
\text { Size }\end{array}$ & $\begin{array}{c}\text { \# of Subjects } \\
\text { per Session }\end{array}$ \\
\hline \hline Standard One-on-One & 1 & $24,30,28$ \\
\hline Unanimity with Rejection Default & 3 & $30,30,30$ \\
\hline Unanimity with Acceptance Default & 3 & $30,30,30$ \\
\hline Majority Rule & 3 & $24,30,30$ \\
\hline
\end{tabular}

Table 2: Sequential Design

\begin{tabular}{|c|c|c|c|c|c|}
\hline $\begin{array}{c}\text { First Ultimatum } \\
\text { Bargaining }\end{array}$ & $\begin{array}{c}\text { Group } \\
\text { Size }\end{array}$ & $\begin{array}{c}\text { \# of Subjects } \\
\text { per Session }\end{array}$ & $\begin{array}{c}\text { Second Ultimatum } \\
\text { Bargaining }\end{array}$ & $\begin{array}{l}\text { Group } \\
\text { Size }\end{array}$ & $\begin{array}{c}\text { \# of Subjects } \\
\text { per Session }\end{array}$ \\
\hline One-on-One & 1 & $28^{+}$ & Majority Rule & 3 & 24 \\
\hline Majority Rule & 3 & 24 & One-on-One & 1 & 24 \\
\hline
\end{tabular}

Bargaining Procedure. Subjects were informed that they had to bargain over 100 points. For the group-on-group treatments, the task of each pair of groups was to divide 100 points in each period using the following rules: a) group A had to make a final offer of points to group B; b) to make a final offer, each group A member had to write and send an offer via computer, each offer being in the range from 0 to 100 points; c) one of these offers was chosen randomly by the computer as group A final offer to group B; d) upon receiving the final offer, group $B$ members had to decide whether to accept or reject the offer according to the voting rule announced for this session. No communication, except as explicitly discussed in this and next paragraph, was allowed among participants. For the one-on-one treatment a type A agent had to make and send an offer to a type $B$ agent, and after receiving the offer, the type B agent had to decide on his own whether to accept or reject it.

Information Feedback. For the group-on-group treatments, group A members observed only their own offer and the final offer sent to group B. Group B members observed the final offer, but not the other offers made by group A members. At the end of each round, members of both groups were informed whether the final offer was accepted or rejected, the number of individual acceptance and rejection votes (between 0 and 3) in the responder 
group, and the number of points obtained by their group in that round. For the one-on-one treatment, each agent learned whether the offer was accepted or rejected and her own amount of points obtained for that round.

Payoffs. The final payoff for each treatment in the independent design was determined by randomly selecting one of the 10 real rounds. For the sequential design, the final payoff for each bargaining situation was determined by randomly selecting one round out of 10 real periods of each game played. The pay for the chosen period was calculated as follows: Each group member got $\$ 2.6$ Mexican pesos (about 23 US cents) for each point obtained by her own group, in addition to the basic amount of $\$ 20$ pesos (roughly US\$1.75) for participation. Thus, each pair of groups effectively bargained over $\$ 780$ pesos (around US\$68 in year 2004 when the first experimental sessions were conducted). For the one-on-one treatment, each pair of agents had to bargain over $\$ 260$ pesos. In the sequential design one period was chosen for each of the games played, so that size of the pie was equal to $\$ 780$ pesos ( $\$ 260$ pesos) for each game.

\section{Experimental Results}

This section sees whether the comparative static predictions of the theory are borne out with the data from the laboratory. In particular, we concentrate on measuring how different voting rules affect individual and group rejection rates and proposals. ${ }^{4}$

\footnotetext{
${ }^{4}$ Tables 6 and 7 , at the end, show a summary statistics of the experimental results. In particular, it describes for the one-on-one treatment the distribution of individual proposals and rejections aggregated across all ten periods. The offer range indicates the amount of points a proposer is willing to give to a responder. Consider, for example, the offer range from 35 to 39 . In the one-on-one treatment, the number of proposals within this range was 86 out of a total of 530 offers, $16.2 \%$ (86/530). Likewise, the number of offers in this range rejected by the responders was 18 , resulting in the empirical rejection rate of $20.9 \%(18 / 86)$.

In the same table, we also provide the data for the group-on-group treatments. As in the one-on-one case, consider the offer range from 35 to 39 for the majority rule treatment. The total number of individual proposals within this range was 77 , which makes up $15.1 \%$ of the total of 510 offers in this treatment. Since just 1 out of 3 proposals was randomly chosen to be sent to a responder group, the group proposals are simply a random selection of the individual ones. The number of group proposals within this range was 30 out of a total of 170 offers sent. Therefore, the group offers proportion was 17.6\% (30/170). Since all 3 members of a responder group received the same offer, the individual rejection number within this range was 29 ; with a total of 90 observations $(30 \times 3)$, the individual rejection rate for this range was $32.2 \%(29 / 90)$. At group level, the number of rejections within this range was 10 out of 30 , resulting in a $33.3 \%$ (10/30) group rejection rate. At the bottom of
} 
Elbittar et al.: Group Decision-Making and Voting in Ultimatum Bargaining

\subsection{Responder Behavior}

We begin by checking whether individual voting behavior and group rejection rates differ across treatments, conditional on the offer size. In particular, the model suggests that individual rates of voting for rejection should not differ across different treatments and that the group rejection rate for unanimity with rejection default should be higher than for the one-on-one treatment, and these two higher than for the unanimity with acceptance default. Meanwhile, majority rule rejection rate should be higher than for the one-on-one treatment for $P(x)<1 / 2$ and lower, otherwise.

In what follows we separately analyze the individual and group decisions. At individual level, each individual decision to accept (or vote to accept) or to reject (or vote to reject) a specific offer is treated as one decision outcome, while at group level, a decision outcome is each group decision to accept or to reject an offer. At each level we have a total of six different treatments for which we observe rejection behavior: $i$ ) decisions to accept/reject by individuals who played a one-on-one ultimatum bargaining only; ${ }^{5} i i-i v$ ) decisions by individuals/groups who played a group-on-group ultimatum bargaining under a specific voting rule only; $v$ ) decisions by individuals who played a one-on-one ultimatum bargaining having previously experienced playing group-on-group ultimatum bargaining under the majority voting rule; and vi) decisions by individuals/groups who played a group-on-group ultimatum bargaining under the majority voting rule having previously experienced playing one-on-one ultimatum bargaining game.

Subjects played multiple rounds of the bargaining game and each individual's actions over time are clearly not independent. For this reason, as well as for comparison with such earlier studies as Bornstein and Yaniv (1998) and Messick et. al. (1997), in which subjects played the game only once, we initially attempted to test our hypotheses using only data from a single period. However, the results of our statistical analysis using data only from the first period are inconclusive, as are the results using data from the last period. ${ }^{6}$ While we are unable to reject the hypothesis that individual probabilities of voting to reject, conditional on offer size, are the same across the treatments, neither do group rejection probabilities vary across treatments in a statistically significant way. But if agents' individual voting behavior is the

the table some summary statistics are shown for the offers made and rejected.

${ }^{5}$ Here and in case $(v)$ below, group and individual decisions are, clearly, tautologically the same.

${ }^{6}$ Detailed regression results are available from the authors upon request. 
same in different treatments, this immediately implies that the group outcomes have to be different. Simply plugging numbers into a formula in section 2 one would observe that if the probability of individual voting to reject a given offer is, say $25 \%$, then under unanimity with acceptance default the three-person group will only reject with less than $2 \%$ probability, while the unanimity with rejection default will result in the rejection probability of nearly $58 \%$. Since the two sets of coefficients cannot simultaneously be equal to zero, no matter the actual behavior of individuals, we infer that our sample size is insufficient to make any conclusions from a single period of observations. ${ }^{7}$ In what follows we instead present results of the statistical analysis involving data from all experimental rounds. ${ }^{8}$

Table 3 reports estimates of the following two rejection equations at individual and group level:

$$
\begin{aligned}
& \text { Reject }_{i t}=1\left\{\text { Intercept }+\beta_{\text {offer }} \text { Offer } \text { It }_{i t}\right. \\
& +\beta_{\text {urd }} U R D+\beta_{\text {uad }} U A D+\beta_{m r} M R \\
& +\beta_{\text {expgog }} E X P G N G+\beta_{\text {expono }} \text { EXPONO } \\
& \left.+\beta_{\text {per }} \operatorname{Per}+v_{i}+\epsilon_{i t} \geq 0\right\} \\
& \text { Reject }_{k t}=1\left\{\text { Intercept }+\gamma_{\text {offer }} \text { Offer } \text { f }_{k t}\right. \\
& +\gamma_{u r d} U R D+\gamma_{u a d} U A D+\gamma_{m r} M R \\
& +\gamma_{m r o} M R \times O f f e r_{k t}+\gamma_{\text {expgog }} \text { EXPGNG }+\gamma_{\text {expono }} \text { EXPONO } \\
& \left.+\gamma_{\text {per }} \text { Per }+w_{k}+\mu_{k t} \geq 0\right\}
\end{aligned}
$$

\footnotetext{
${ }^{7}$ One should note, that our sample size is not particularly small by the literature standards. Thus, Bornstein and Yaniv (1998) have only 20 one-on-one and 20 group-on-group observations (they only observe final group decisions). They observe only 2 rejections, making it difficult to make conclusions about rejection probabilities. Our failure to establish significant results using single-period data also closely parallels that of Slonim and Roth (1998) in their study of high-stakes ultimatum bargaining. As they discuss in detail, a major problem is the lack of exogenous variation of offers, which makes it hard to estimate the difference in conditional rejection probabilities across treatments from one period data only, without observing many more subjects than is typical in a laboratory experiment.

${ }^{8}$ In doing this we have adjusted our statistical analysis for individual-specific effects. We also report both individual- and group-level results to provide evidence that insignificance of individual-level coefficients is not merely due to insufficient sample size, as in the singleperiod case.
} 
Elbittar et al.: Group Decision-Making and Voting in Ultimatum Bargaining

Table 3: Probability of Offer Rejection for All Periods: Logit Estimation

\begin{tabular}{|c|c|c|}
\hline Coefficients & Individual & Group \\
\hline \multirow[t]{2}{*}{ Intercept } & $6.214^{* * *}$ & $9.330^{* * *}$ \\
\hline & $(0.711)$ & $(1.591)$ \\
\hline \multirow[t]{2}{*}{ Offer } & $-0.230^{* * *}$ & $-0.332^{* * *}$ \\
\hline & $(0.017)$ & $(0.046)$ \\
\hline \multirow[t]{2}{*}{ Unanimity with Rejection Default } & 0.643 & $2.981^{* * *}$ \\
\hline & $(0.605)$ & $(0.843)$ \\
\hline \multirow[t]{2}{*}{ Unanimity with Acceptance Default } & 0.310 & $-2.872^{* *}$ \\
\hline & $(0.593)$ & $(1.016)$ \\
\hline \multirow[t]{2}{*}{ Majority Rule } & 0.265 & -3.727 \\
\hline & $(0.604)$ & $(2.137)$ \\
\hline \multirow[t]{2}{*}{ Majority $\times$ Offer } & $(-)$ & 0.091 \\
\hline & $(-)$ & $(0.061)$ \\
\hline \multirow[t]{2}{*}{ Experienced Group-on-Group Ultimatum Bargaining } & -0.959 & 0.343 \\
\hline & $(0.755)$ & $(1.475)$ \\
\hline \multirow[t]{2}{*}{ Experienced One-on-One Ultimatum Bargaining } & $-1.908^{* *}$ & -1.377 \\
\hline & $(0.716)$ & $(1.301)$ \\
\hline \multirow[t]{2}{*}{ Period } & $-0.078^{* *}$ & -0.107 \\
\hline & $(0.030)$ & $(0.060)$ \\
\hline \# of individuals & 170 & 523 \\
\hline \# of obs. per individual (min) & 10 & 1 \\
\hline Total \# of obs. & 1940 & 1000 \\
\hline Log Likelihood & -614.8 & -297.3 \\
\hline
\end{tabular}

${ }^{*}: p<0.05,{ }^{* *}: p<0.01$ and $^{* * *}: p<0.001$.

Note: The number in parentheses below each coefficient represents the coefficient standard error. 
In both equations $1\{\cdot\}$ is an indicator function that takes the value of one if the left-hand side of the inequality inside the brackets is greater than or equal to zero and the value zero otherwise. Model (1) checks whether different voting rules affect individual rejection decision in addition to the offer size, where $O f f_{e r} r_{i t}$ is the offer individual $i$ receives from 0 to 100 at period $t$. Model (2) does the same for group rejection decision, where Offer $r_{k t}$ is the offer group $k$ receives from 0 to 100 at period $t$. $U R D, U A D$ and $M R$ are dummies for each of the voting rules; EXPGNG is a dummy for those individuals (or groups members) who played one-on-one ultimatum bargaining having first experienced playing group-on-group ultimatum bargaining under the majority voting rule; EXPONO is a dummy for those individuals (or groups) who played group-on-group ultimatum bargaining under the majority voting rule having first experienced playing one-on-one ultimatum bargaining; and Per is a variable for every period, treating time as a continuous variable. We use a random effect logit model to account for individual and group variability, where $v_{i}$ and $w_{k}$ are i.i.d., $N\left(0, \sigma_{v}^{2}\right)$ and $N\left(0, \sigma_{w}^{2}\right)$, respectively. Likewise, $\epsilon_{i t}$ and $\mu_{i t}$ are i.i.d. logistic distributed with mean zero and variance $\sigma_{\epsilon}^{2}=\sigma_{\mu}^{2}=\sigma^{2} / 3$, independently of $v_{i}$ and $w_{k}$.

For both models we expect the offer size coefficient to be less than zero $\left(\beta_{\text {offer }}<0\right.$ and $\left.\gamma_{\text {offer }}<0\right)$, meaning that the rejection probability should be lower for higher offers. For model (1), we expect all treatment coefficients be equal to zero $\left(\beta_{\text {urd }}=\beta_{\text {uad }}=\beta_{m r}=0\right)$. For model (2), we should expect that the unanimity treatment coefficients differ in sign $\left(\gamma_{\text {urd }}>0, \gamma_{\text {uad }}<0\right)$, where a positive coefficient should indicate a higher probability of rejection for a given offer than a negative coefficient. This specification takes into account for majority rule the possibility of higher rejection rates for lower offers and lower rejection rates for higher offers $\left(\gamma_{m r}>0\right.$ and $\left.\gamma_{m r_{o}}<0\right)$.

The first numerical column in Table 3 shows the estimates of equation (1). None of the treatment coefficients $\left(\beta_{\text {urd }}, \beta_{\text {uad }}\right.$ and $\left.\beta_{m r}\right)$ in this model show individual significance for a $p<0.05$. A $\chi^{2}$ test indicates that the null hypothesis of $\beta_{\text {urd }}=\beta_{\text {uad }}=\beta_{m r}=0$ cannot be rejected for a $p=0.82$. Our estimation does show that subjects with experience in one-on-one ultimatum bargaining game tend to submit lower offers. In addition, a $\chi^{2}$ test indicates that the null hypothesis of $\beta_{\text {expgog }}=\beta_{\text {expono }}=0$ cannot be rejected for a $p=0.39$. On the other hand, time-period coefficient being different from zero can be rejected for a $p=0.003$. This indicates that players are willing to reduce the probability of rejection over time. Finally, a $\chi^{2}$ test indicates that the null hypothesis of the voting rules, experience and time period coefficients 
being jointly equal to zero can be rejected for a $p<0.0001$. This result indicates that this model performs better than a specification that does not include these variables, indicating a possible role, at least, for experience and time period in explaining individual rejection probabilities. ${ }^{9}$

The last column in Table 3 shows the same estimates of equation (2). The offer size coefficient $\left(\gamma_{\text {offer }}\right)$ is correct in sign and significant. Likewise, the coefficients for both unanimity treatments $\left(\gamma_{u r d}\right.$ and $\left.\gamma_{u a d}\right)$ are significant and have the expected signs. In particular, under URD the rejection probability increases by $19.3 \%$, while under UAD it increases by $8 \%$. On the other hand, the majority rule coefficients $\left(\gamma_{m r}\right.$ and $\left.\gamma_{m r o}\right)$ exhibit opposite signs to what was expected, though the $\chi^{2}$ test result indicates that the null hypothesis of $\gamma_{m r}=$ $\gamma_{m r o}=0$ cannot be rejected $(p=0.134)$, indicating that we cannot really distinguish between the on-on-one and the group-on-group majority voting rule treatment in terms of rejection probability. Overall, a $\chi^{2}$ test result indicates that the null hypothesis of $\gamma_{u r d}=\gamma_{u a d}=\gamma_{m r}=\gamma_{m r o}=0$ can be rejected for a $p<0.0001$, favoring the joint significance of these treatment variables. None of the experience treatment and time-period coefficients show individual (or joint) significance for a $p<0.05$. Thus, experience and time do not contribute to explaining group rejection rate variations. Finally, a $\chi^{2}$ test indicates that the null hypothesis of the voting rules, experience and time period coefficients being jointly equal to zero can be rejected for a $p<0.0001$. This result indicates that this model performs better than a specification that does not include these variables. ${ }^{10}$

Summing up, the rejection probability estimations using the data set from all ten periods show how different voting rules affect individual and group responses in ultimatum bargaining. On one hand, individuals tend to respond by voting in the same way whether they are deciding within a group or alone, which supports our model, as developed in the theory section. In particular, it suggests that we are justified in modeling agents as only caring about the distribution of monetary payoffs. On the other hand, different voting rules affect group rejection probabilities as expected. Not surprisingly, smaller offers result in higher rejection probability. Finally, we observe that time does matter in predicting individual behavior. In particular, the same offers are less likely

\footnotetext{
${ }^{9}$ A likelihood-ratio test for this regression that compares the pooled with the panel estimator rejects the null hypothesis that panel-level variance component is unimportant for a $p<0.0001$.

${ }^{10} \mathrm{~A}$ likelihood-ratio test for this regression that compares the pooled with the panel estimator rejects the null hypothesis that panel-level variance component is unimportant for a $p<0.0001$.
} 
The B.E. Journal of Economic Analysis \& Policy, Vol. 11 [2011], Iss. 1 (Contributions), Art. 53

Table 4: Proposer Behavior

\begin{tabular}{|c|c|}
\hline Coefficients & Proposals \\
\hline \hline Intercept & $40.127^{* * *}$ \\
\hline & $(1.390)$ \\
\hline Unanimity with Rejection Default & $3.677^{*}$ \\
\hline & $(1.823)$ \\
\hline Unanimity with Acceptance Default & 1.873 \\
\hline & $(1.930)$ \\
\hline Majority Rule & -3.637 \\
\hline & $(2.004)$ \\
\hline Period & -0.119 \\
\hline & $(0.096)$ \\
\hline URD $\times$ Period & 0.098 \\
\hline & $(0.141)$ \\
\hline UAD $\times$ Period & $-0.645^{* * *}$ \\
\hline & $(0.140)$ \\
\hline MR $\times$ Period & 0.168 \\
\hline & $(0.138)$ \\
\hline$\#$ of Obs. & 1910 \\
\hline
\end{tabular}

${ }^{*}: p<0.05,{ }^{* *}: p<0.01$ and $^{* * *}: p<0.001$.

Note: The number in parentheses below each coefficient represent the coefficient standard error.

to be rejected over time. Finally, subjects' experience playing as a members of a group (or as individuals) does not influence rejection rates when playing as individuals (or as a members of a group). We conclude that our qualitative comparative static predictions for the rejection probabilities seem to hold. 
Elbittar et al.: Group Decision-Making and Voting in Ultimatum Bargaining

\subsection{Proposer Behavior}

Given the differences in group rejection probabilities for different voting rules, we should expect changes in offers across treatments. We consider the following specification to estimate whether the size of offers differs across treatments for all periods:

$$
\begin{aligned}
& \text { Offer } \text { fit }_{i \text { Intercet }}+\alpha_{\text {urd }} U R D+\alpha_{\text {uad }} U A D+\alpha_{m r} M R+\delta_{\text {per }} \text { Per } \\
& +\delta_{\text {perurd }} \text { Per } \times U R D+\delta_{\text {peruad }} \operatorname{Per} \times U A D+\delta_{\text {permr }} \text { Per } \times M R+v_{i}+\epsilon_{i t}
\end{aligned}
$$

where $O f f e r_{i}$ is the offer proposer $i$ sent from 0 to 100. We expect the offer size coefficient for unanimity with rejection default to be greater than zero $\left(\alpha_{\text {urd }}>0\right)$, meaning that compared to the one-on-one treatment proposers should be willing to offer more given the high rejection probability behind this voting rule. For unanimity with acceptance default, we should expect a coefficient less than zero $\left(\alpha_{\text {uad }}<0\right)$, which means that compared to the one-on-one treatment proposers should be willing to offer less given the low probability of rejection. Compared to the one-on-one treatment, proposers facing majority rule should be willing to offer less when $P(x)<\frac{1}{4}$ and more otherwise. Therefore, it is difficult to predict the coefficient sign associated to this treatment. ${ }^{11}$ We use a random effect model to account for individual variability, where $v_{i}$ is the random disturbance characterizing the $i$ th individual and is constant through time and $\epsilon_{i t}$ is the random disturbance that varies independently across time and individuals. This specification allows also the possibility of a different dynamic within each treatment. ${ }^{12}$

\footnotetext{
${ }^{11} \mathrm{We}$ also considered a specification introducing dummies for subjects who experience making offers under different bargaining situations. However, the corresponding coefficients were not jointly different from zero for a $p<0.05$.

${ }^{12}$ In the one-on-one and majority rule treatments, three subjects reported in the postsession questionnaire initial confusion about the meaning of the offer (i.e., whether it was the offer to the responder or the fraction retained by the proposer that was being sent). These same three subjects submitted offers far in excess of 50\%, apparently under the impression that they were doing the opposite. Thus, in the one-on-one treatment such a subject offered 100 for 8 consecutive periods and then 45 twice (possibly, upon realization of the mistake). We believe this behavior confirms the self-reported initial misunderstanding of the instructions by the subject in question. Consequently, we decided to exclude all of his proposals, leaving us with 520 individual offers out of a total of 530. Likewise, in the majority rule treatment there was a subject who for 5 periods in a row offered over 90, followed this by an offer of 50 and then 4 offers of less than 15; and another subject who offered 5 times more than 90, twice between 70 and 80, twice 50 and concluded with an offer of 1 in the final round. After excluding these two subjects' offers, we consider 490 individual offers out of a total of 510 individual offers. When these offers were included, predictably,
} 
Table 4 shows the results of the random effect estimation. Our estimation shows that the time period coefficient $\left(\delta_{\text {period }}\right)$ is significant for a $p<0.001$, implying that proposers were willing to offer less over time. The unanimity with rejection default coefficient is positive and different from zero $(p<0.05)$, indicating that proposers tend to offer more than in the one-on-one treatment. The signs of the majority rule and unanimity with acceptance default coefficients are not significantly different from zero for a $p=0.42$ and $p=0.33$, respectively. However, a $\chi^{2}$ test result indicates that the null hypothesis of $\delta_{u r d}=\delta_{u a d}=\delta_{m r}=0$ can be rejected for a $p<0.001$. Our specification allows for a difference in the dynamic within each treatment. A $\chi^{2}$ test result indicates that the null hypothesis of $\delta_{\text {perurd }}=\delta_{\text {peruad }}=\delta_{\text {permr }}=0$ can be rejected for a $p<0.001$, confirming the presence of such difference. In fact, $\delta_{\text {peruad }}$ is clearly negative (significance at $p<0.001$ ), which, compared with the insignificant sign of $\alpha_{\text {uad }}$, suggests that agents may be moving towards a correct response. ${ }^{13}$

Summing up the results, our estimations indicate that offers decrease over time; offers are higher for the unanimity with rejection default than for other treatments; offers are not significantly different for the other two voting rules compared to the control treatment; and offers decrease over time in the unanimity with acceptance default.

\subsubsection{One-on-One vs. Group-on-Group Majority Rule}

Sequential treatment was designed to try to distinguish between the one-onone and majority group behavior. The same individuals were proposers in both the one-on-one and majority rule games and our model suggests that we should expect the same participants to make different individual offers in the two bargaining situations. To test this hypothesis we consider the following specification:

they moved the average of the individual treatment benchmark up, which made the URD effects less significant (significance surviving only at $6 \%$ level), but the UAD effects more significant than reported in what follows. For both unanimity treatments, no subjects offers were excluded.

${ }^{13}$ From the raw data we observe that in the unanimity with acceptance default treatment proposers were exposed to a higher-than-expected number of actual group rejections in early rounds (this difference was not statistically significant), possibly making them cautious about aggressive offers. The sign of the $\delta_{\text {peruad }}$ suggests that, as the impact of those early rejections wore off, the proposers did start to be more aggressive, as predicted by the model. 
Elbittar et al.: Group Decision-Making and Voting in Ultimatum Bargaining

Table 5: Group-on-Group Majority Rule vs. One-on-One Ultimatum Bargaining

\begin{tabular}{|c|c|}
\hline Coefficients & Average Offer MR \\
\hline \multirow[t]{2}{*}{ Intercept } & $21.275^{* * *}$ \\
\hline & $(6.066)$ \\
\hline \multirow[t]{2}{*}{ Average Offer ONO } & $0.521^{* * *}$ \\
\hline & $(0.145)$ \\
\hline \# of Obs. & 24 \\
\hline
\end{tabular}

$$
O f f e r_{i t}^{M R}=\alpha+\beta O f f e r_{i t}^{O N O}+v_{i}+\epsilon_{i t}
$$

where $O f f e r_{i t}^{M R}$ is the average offer proposer $i$ made under the group-ongroup ultimatum bargaining where the receiver group have to decide whether to accept under the majority voting rule and $O f f e r_{i t}^{O N O}$ is the average offer proposer $i$ made in the one-on-one ultimatum bargaining. We should expect the offer size coefficient under the one-on-one ultimatum bargaining be greater than zero and less than one $(1>\beta>0)$, meaning that those individuals that were less (more) aggressive as proposer in a one-on-one ultimatum bargaining becomes somewhat more (less) aggressive when playing against groups, and vice versa. ${ }^{14}$ Table 5 shows estimation for this specification. ${ }^{15}$ Our estimation shows that average offer coefficient $(\beta)$ is significant for a $p<0.001$. We could reject the null hypothesis that this coefficient was greater than or equal to one (less than or equal to zero) for a $p<0.001$. This result is consistent with the expected changes in the individual average offers across bargaining situations. Figure 1 shows for each individual his/her average offers under each of the bargaining situations (note our regression crossing the $45^{\circ}$ line). ${ }^{16}$

\footnotetext{
${ }^{14}$ This does not mean that agents "aggressiveness ranking" should switch - the same agents would be making relatively high (respectively, relatively low) offers in both situations.

${ }^{15}$ We also evaluated another model specification, where a dummy variable for the order in which agents played the games is considered. For this specification, we could not reject the null hypothesis that this coefficient was different from zero for a $p=0.41$. Therefore, the order in which agents find themselves in different bargaining situations does not contribute to explaining offer variation.

${ }^{16}$ We also consider another specification where we included a dummy variable for controling the order of the treatment. This dummy was not significant, so we decided to drop it from our estimation.
} 
The B.E. Journal of Economic Analysis \& Policy, Vol. 11 [2011], Iss. 1 (Contributions), Art. 53

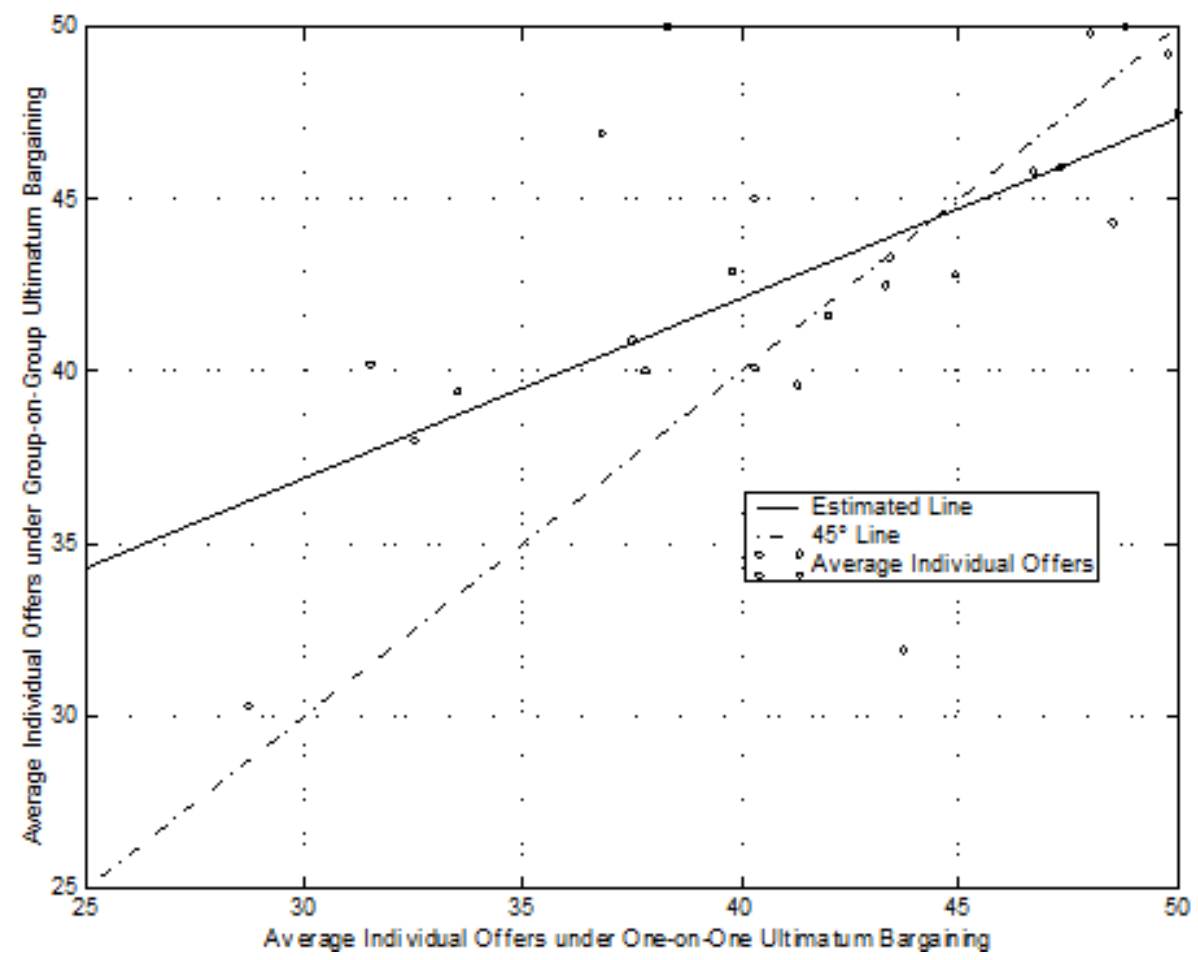

Figure 1: Average Individual Offers

\section{Conclusions}

In this paper we provide a comparison between four different treatments of ultimatum bargaining: the one-on-one bargaining and three different groupon-group games differentiated by the controlled decision rule used on the responder side to agree on acceptance or rejection. In the latter three treatments the group members share the outcome of the bargaining, but are completely isolated in a setting which minimizes the possibility of them forming any sort of true group ties or within-group strategic interactions. The results of our experiments seem to support the following conclusions:

Firstly, we cannot reject the hypothesis that individual responder behavior is the same in all four treatments. The absence of difference between the behavior inside and outside the group suggests that sharing in the outcomes, on its own, might not be sufficient to form any group feelings that might affect individual behavior. Of course, the individual responder behavior does generate the predictable and (in this case, statistically significant) differences in 
group responder behavior, which creates incentives for the proposers to adjust their offers depending on the treatment.

Secondly, we can reject the hypothesis that the proposer behavior is the same in all four treatments. In particular, in the unanimity with rejection default treatment proposers are clearly substantially more cautious than in other treatments, which indicates that they correctly respond to the increased difficulty of obtaining acceptance of their proposals. We also observe differences in proposers' behavior between the one-on-one bargaining and the other treatments of group bargaining. In particular, while in the unanimity with acceptance default treatment we fail to observe proposers to be on average more aggressive initially, we do observe them becoming more aggressive with time. One reason for this delay may be that, though the observed difference in responder behavior between the unanimity with acceptance default and the one-on-one treatments is not statistically significant, the realization of the individual conditional rejection probability in this treatment happened to be somewhat high. 
The B.E. Journal of Economic Analysis \& Policy, Vol. 11 [2011], Iss. 1 (Contributions), Art. 53

Table 6: Summary of Experimental Results: One-on-One and MR Group-on-group Treatments

\begin{tabular}{|c|c|c|c|c|c|c|}
\hline \multirow{2}{*}{$\begin{array}{c}\text { Offer } \\
\text { Range }\end{array}$} & \multicolumn{2}{|c|}{ One-on-One } & \multicolumn{4}{|c|}{ Majority Rule } \\
\cline { 2 - 7 } & Ind. Off. & Ind. Rej. & Ind. Off. & Grp. Off. & Ind. Rej. & Grp. Rej. \\
\hline \hline$>50$ & 2.8 & 0.0 & 5.7 & 4.7 & 0.0 & 0.0 \\
\hline & $(15)$ & $(0)$ & $(29)$ & $(8)$ & $(0)$ & $(0)$ \\
\hline$=50$ & 11.5 & 1.6 & 11.0 & 13.5 & 2.9 & 0.0 \\
\hline & $(61)$ & $(1)$ & $(56)$ & $(23)$ & $(2)$ & $(0)$ \\
\hline $45-49$ & 18.1 & 5.2 & 18.4 & 16.5 & 7.1 & 3.6 \\
\hline & $(96)$ & $(5)$ & $(94)$ & $(28)$ & $(6)$ & $(1)$ \\
\hline $40-44$ & 28.3 & 7.3 & 21.8 & 18.8 & 17.7 & 9.4 \\
\hline & $(150)$ & $(11)$ & $(111)$ & $(32)$ & $(17)$ & $(3)$ \\
\hline $35-39$ & 16.2 & 20.9 & 15.1 & 17.6 & 32.2 & 33.3 \\
\hline & $(86)$ & $(18)$ & $(77)$ & $(30)$ & $(29)$ & $(10)$ \\
\hline $30-34$ & 9.1 & 12.5 & 10.4 & 8.8 & 24.4 & 20.0 \\
\hline & $(48)$ & $(6)$ & $(53)$ & $(15)$ & $(11)$ & $(3)$ \\
\hline $25-29$ & 8.3 & 38.6 & 12.0 & 11.8 & 30.0 & 25.0 \\
\hline & $(44)$ & $(17)$ & $(61)$ & $(20)$ & $(18)$ & $(5)$ \\
\hline$<25$ & 5.7 & 80.0 & 5.7 & 8.2 & 57.1 & 64.3 \\
\hline & $(30)$ & $(24)$ & $(29)$ & $(14)$ & $(24)$ & $(9)$ \\
\hline All Off. & 100.0 & 15.5 & 100.0 & 100.0 & 21.0 & 18.2 \\
\hline & $(530)$ & $(82)$ & $(510)$ & $(170)$ & $(107)$ & $(31)$ \\
\hline Statistics & & & & & & \\
\hline Avg. & 40 & 27 & 40 & 40 & 31 & 28 \\
\hline Med. & 40 & 30 & 40 & 40 & 35 & 31 \\
\hline s.d. & 12 & 12 & 13 & 15 & 11 & 11 \\
\hline
\end{tabular}

Note: Numbers represent percentage of offers within each range.

The number in parentheses below each percentage represents

the number of times the occurrence was observed. 
Elbittar et al.: Group Decision-Making and Voting in Ultimatum Bargaining

Table 7: Summary of Experimental Results: URD and UAD Group-on-group Treatments

\begin{tabular}{|c|c|c|c|c|c|c|c|c|}
\hline \multirow{2}{*}{$\begin{array}{c}\text { Offer } \\
\text { Range }\end{array}$} & \multicolumn{2}{|c|}{ Unanimity with Rejection Default } & \multicolumn{3}{|c|}{ Unanimity with Acceptance Default } \\
\cline { 2 - 9 } & Ind. Off. & Grp. Off. & Ind. Rej. & Grp. Rej. & Ind. off. & Grp Off. & Ind. Rej. & Grp. Rej. \\
\hline \hline$>50$ & 11.1 & 9.3 & 0.0 & 0.0 & 8.4 & 8.7 & 2.6 & 0.0 \\
\hline & $(50)$ & $(14)$ & $(0)$ & $(0)$ & $(38)$ & $(13)$ & $(1)$ & $(0)$ \\
\hline$=50$ & 14.7 & 10.0 & 0.0 & 0.0 & 2.4 & 3.3 & 0.0 & 0.0 \\
\hline & $(66)$ & $(15)$ & $(0)$ & $(0)$ & $(11)$ & $(5)$ & $(0)$ & $(0)$ \\
\hline $45-49$ & 32.7 & 36.7 & 5.5 & 16.4 & 13.8 & 16.7 & 4.0 & 36.0 \\
\hline & $(147)$ & $(55)$ & $(9)$ & $(9)$ & $(62)$ & $(25)$ & $(3)$ & $(9)$ \\
\hline $40-44$ & 20.2 & 20.0 & 14.4 & 30.0 & 24.4 & 26.0 & 9.4 & 2.6 \\
\hline & $(91)$ & $(30)$ & $(13)$ & $(9)$ & $(110)$ & $(39)$ & $(11)$ & $(1)$ \\
\hline $35-39$ & 8.2 & 8.7 & 20.5 & 46.2 & 23.8 & 18.7 & 25.0 & 14.3 \\
\hline & $(37)$ & $(13)$ & $(8)$ & $(6)$ & $(107)$ & $(28)$ & $(21)$ & $(4)$ \\
\hline $30-34$ & 8.9 & 10.0 & 40.0 & 80.0 & 11.6 & 12.7 & 54.4 & 15.8 \\
\hline & $(40)$ & $(15)$ & $(18)$ & $(12)$ & $(52)$ & $(19)$ & $(31)$ & $(3)$ \\
\hline $25-29$ & 2.2 & 2.7 & 75.0 & 100.0 & 6.7 & 4.0 & 44.4 & 16.7 \\
\hline & $(10)$ & $(4)$ & $(9)$ & $(4)$ & $(30)$ & $(6)$ & $(8)$ & $(1)$ \\
\hline$<25$ & 2.2 & 2.7 & 91.7 & 100.0 & 8.9 & 10.0 & 64.4 & 33.3 \\
\hline & $(9)$ & $(4)$ & $(11)$ & $(4)$ & $(40)$ & $(15)$ & $(29)$ & $(5)$ \\
\hline All Off. & 100.0 & 100.0 & 15.1 & 29.3 & 100.0 & 100.0 & 23.1 & 15.3 \\
\hline & $(450)$ & $(150)$ & $(68)$ & $(44)$ & $(450)$ & $(150)$ & $(104)$ & $(23)$ \\
\hline Statistics & & & & & & & & \\
\hline Avg. & 44 & 43 & 31 & 34 & 38 & 39 & 29 & 28 \\
\hline Med. & 45 & 45 & 30 & 35 & 39 & 40 & 30 & 33 \\
\hline & 10 & 10 & 12 & 10 & 11 & 12 & 11 & 10 \\
\hline
\end{tabular}

Note: Numbers represent percentage of offers within each range. The number

in parentheses below each percentage represents the number of times

the occurrence was observed. 
The B.E. Journal of Economic Analysis \& Policy, Vol. 11 [2011], Iss. 1 (Contributions), Art. 53

\section{Appendix: Experimental Instructions}

The following is the verbatim translation (from Spanish into English) of experimental instructions administered to subjects at ITAM (the Spanish original is available from the authors upon request).

Instructions Group-on-Group

This is an experiment about decision-making. The instructions are simple and if you follow them carefully and take good decisions, you can earn a CONSIDERABLE AMOUNT OF MONEY, which will be PAID YOU IN CASH at the end of the experiment.

General Proceedings

In this experiment you will participate as a member of a GROUP A or a GROUP B. Your participation as a part of one of these two groups shall be determined at the beginning of the experiment and will be constant during the entire session. Each group shall consist solely of three (3) participants.

The experiment shall consist of 12 periods: two practice periods, and 10 periods played for money, one of which shall be randomly selected at the end of the experiment to determine your final pay. For this reason you should consider each period as if it were "the chosen period" for your pay.

At the beginning of each period, each TYPE A GROUP will interact with a TYPE B GROUP. The formation of pairs of GROUPS A and B will be done randomly. Likewise, the membership composition of each group will change in a random fashion, so that each participant will form a part of a new GROUP (of the same type) at the beginning of each period.

Specific Proceedings

In each period the task of each pair of groups is to try to divide 100 points using the following rules.

1) The members of GROUP A must make an offer of points to members of GROUP B.

1.1) To make the final offer from GROUP A to GROUP B each member of GROUP A must write and send an offer via the computer. Each offer must be in the range of 0 to 100 points.

1.2) After that, one of these offers made shall be chosen randomly by the computer as the final offer of GROUP A to GROUP B.

2) The final offer of GROUP A shall be sent to each member of GROUP B. After observing the offer sent, the members of GROUP B must decide if they accept of reject the offer according to the following rule: 
The offer is considered accepted when every one of the members of the group votes to accept it. Otherwise it is considered rejected. ${ }^{17}$

2.1) If GROUP B rejects the offer, no GROUP receives any pay.

2.2) If GROUP B accepts the offer, the GROUP A receives the amount of 100 points minus the points offered to GROUP B. In its turn, GROUP B receives the amount of points which has been offered by GROUP A.

3) Once taken, the decision to accept or reject the offer of points is final, no counter-offer shall be possible, and the next period shall start with a new grouping of participants for each group type.

Payment Proceedings

Once the 10 periods played for money are over, one of them will be chosen randomly to determine the final pay. For this reason, you should consider each period as if it were final "chosen period" for your pay.

The pay for the chosen period shall be calculated as follows: Each member of each group shall get $\$ 2.6$ pesos for each point obtained by the group to which she $\backslash$ he belongs, in addition to the basic amount of $\$ 20$ pesos for participation.

At the end of the session, each of the participants shall be called by the identification number assigned by the computer at the beginning of the experiment to receive his/her pay in a sealed envelope, thus ensuring the complete anonymity of his/her decisions and their results.

Instructions One-on-One

This is an experiment about decision-making. The instructions are simple and if you follow them carefully and take good decisions, you can earn a CONSIDERABLE AMOUNT OF MONEY, which will be PAID YOU IN CASH at the end of the experiment.

General Proceedings

In this experiment you will participate as a TYPE A or TYPE B AGENT.

\footnotetext{
${ }^{17}$ This corresponds to Unanimity with rejection default; instructions for other treatments are as follows.

Unanimity with acceptance default:

"The offer is considered rejected when every one of the members of the group votes to accept it. Otherwise it is considered accepted".

Majority rule:

"The offer is considered accepted when at least two of the members of the group vote to accept it. Otherwise it is considered rejected."
} 
The B.E. Journal of Economic Analysis \& Policy, Vol. 11 [2011], Iss. 1 (Contributions), Art. 53

Your participation as one of these agent types shall be determined at the beginning of the experiment and will be constant during the entire session

The experiment shall consist of 12 periods: two practice periods, and 10 periods played for money, one of which shall be randomly selected at the end of the experiment to determine your final pay. For this reason you should consider each period as if it were "the chosen period" for your pay.

At the beginning of each period, each TYPE A AGENT will interact with a TYPE B AGENT. The formation of pairs of TYPE A and TYPE B AGENTS will be done randomly.

Specific Proceedings

In each period the task of each pair of agents is to try to divide 100 points using the following rules.

1) Each TYPE A AGENT must make an offer of points to a TYPE B AGENT. For this each TYPE A AGENT must write and send an offer via the computer. Each offer must be in the range of 0 to 100 points.

2) After observing the offer sent by the TYPE A AGENT, the TYPE B AGENT must decide if she $\backslash$ he accepts or rejects it.

2.1) If the TYPE B AGENT rejects the offer, no AGENT receives any pay.

2.2) If TYPE B AGENT accepts the offer, the TYPE A AGENT receives the amount of 100 points minus the points offered to TYPE B AGENT. In its turn, TYPE B AGENT receives the amount of points which has been offered by TYPE A AGENT.

3) Once taken, the decision to accept or reject the offer of points is final, no counter-offer shall be possible, and the next period shall start with a new grouping of agent pairs.

Payment Proceedings

Once the 10 periods played for money are over, one of them will be chosen randomly to determine the final pay. For this reason you should consider each period as if it were final "chosen period" for your pay.

The pay for the chosen period shall be calculated as follows: Each agent shall get $\$ 2.6$ pesos for each point obtained, in addition to the basic amount of $\$ 20$ pesos for participation.

At the end of the session, each of the participants shall be called by the identification number assigned by the computer at the beginning of the experiment to receive his/her pay in a sealed envelope, thus ensuring the complete anonymity of his/her decisions and their results. 
Elbittar et al.: Group Decision-Making and Voting in Ultimatum Bargaining

$* \quad * \quad *$

In the sequential treatment, after the completion of the first 10 rounds the subjects were asked to move to a next-door classroom, while the computers were being reinitialized. The subjects were monitored throughout and no communication was allowed. When the subjects returned to the room where the experiment was being conducted, the appropriate instructions were read to them in their entirety before proceeding.

\section{References}

[1] Bornstein, G., and Yaniv, I. (1998), Individual and Group Behavior in the Ultimatum Game: Are Groups More "Rational" Players, Experimental Economics 1: 101-108.

[2] Bornstein, G., Kugler, T. and Ziegelmeyer, A. (2004), Individual and Group Decisions in the Centipede Game: Are Groups More Rational Players? Journal of Experimental Social Psychology 40: 599-605.

[3] Bosman, R., Hennig-Schmidt, H., and vanWinden, F. (2006), Exploring Group Decision Making in a Power-to-take Experiment, Experimental Economics 9: 35-51.

[4] Camerer, C.F. (2003), Behavioral game Theory: Experiments in Strategic Interaction, Russel Sage Foundation and Princeton University, New York.

[5] Cason, T. and Mui, V.-L. (1997), A Laboratory Study of Group Polarization in the Team Dictator Game, Economic Journal 107: 1465-1483.

[6] Charness, G. and Jackson, M. (2007), Group Play in Games and the Role of Consent in Network Formation, Journal of Economic Theory 136: $417-445$

[7] Cox, J.C. (2002), Trust, Reciprocity and Other-regarding Preferences: Groups vs. Individuals and Males vs. Females, in R. Zwick and A. Rapoport, (eds.), Advances in Experimental Business Research, Kluwer Academic Publishers : 331 - 350.

[8] Grosskopf, B. (2003), Reinforcement and Directional Learning in the Ultimatum Game with Responder Competition, Experimental Economics 6: $141-158$. 
The B.E. Journal of Economic Analysis \& Policy, Vol. 11 [2011], Iss. 1 (Contributions), Art. 53

[9] Güth, W., Schmittberger, R., and Schwartz, B. (1982), An Experimental Analysis of Ultimatum Bargaining, Journal of Economic Behavior and Organization 75: 367-388.

[10] Haller, H., and Holden, S. (1997), Ratification requirement and Bargaining Power, International Economic Review 38: 825-851.

[11] Kocher., M.G., and Sutter, M. (2007), Individual versus group behavior and the role of the decision making process in gift-exchange experiments, Empirica 34: 63-88

[12] Kennan, J. and Wilson, R. (1993), Bargaining with Private Information, Journal of Economic Literature 31: 45-104.

[13] Manzini, P., and Mariotti, M.(2005), Alliances and Negotiations, Journal of Economic Theory 121: 128-141.

[14] Messick, D.M., Moore, D.A., and Bazerman, M. (1997), Ultimatum Bargaining with a Group: Understanding the Importance of the Decision Rule, Organizational Behavior and Human Decision Processes 69: 87101.

[15] Putnam, R.D. (1988), Diplomacy and Domestic Politics: the Logic of Two-Level Games, International Organization 42: 328-460.

[16] Robert, C. and Carnevale, P.J. (1997), Group Choice in Ultimatum Bargaining, Organization Behavior and Human Decision Processes 72:256279 .

[17] Romer, T. and Rosenthal, H. (1978), Political resource allocation, controlled agendas, and the status quo, Public Choice 33: 25-43.

[18] Romer, T. and Rosenthal, H. (1979), Bureaucrats versus Voters: On the Political Economy of Resource Allocation by Direct Democracy, Quarterly Journal of Economics 93: 563-587.

[19] Roth, A.E. (1995), Bargaining Experiments, in J. Kagel and A.E. Roth, editors, The Handbook of Experimental Economics, pp. 235-348, Princeton University Press, NJ.

[20] Schelling, T.C. (1980), The Strategy of Conflict, 2nd edition, Harvard University Press, Cambridge, MA and London. 
Elbittar et al.: Group Decision-Making and Voting in Ultimatum Bargaining

[21] Slonim, R. and Roth, A.E. (1998), Learning in High Stakes Ultimatum Games: An Experiment in the Slovak Republic, Econometrica 66: 569596.

[22] Song, F. (2008), Trust and Reciprocity Behavior and Behavioral Forecasts: Individuals versus Group Representatives, Games and Economic Behavior 62: 575-696.

[23] Song, F. (2009), Intergroup Trust and Reciprocity in Strategic Interactions: Effects of Group Decision-Making Mechanisms, Organizational Behavior and Human Decision 108: 164-173.

[24] Wildschut, T., Pinter B., Vevea, J.L., Insko, C.A. and Schopler. J. (2003), Beyond the Group Mind: A Qualitative Review of the InterindividualIntergroup Discontinuity effect, Psychological Bulletin 129: 698-721. 